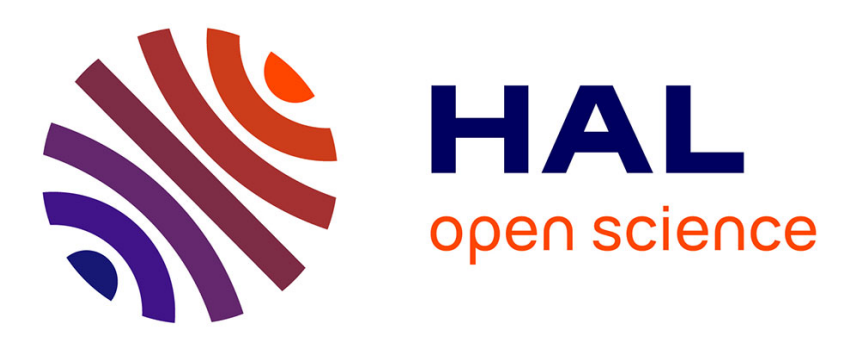

\title{
Feedbacks between deformation and melt distribution in the crust-mantle transition zone of the Oman ophiolite
}

Katherine Higgie, Andrea Tommasi

\section{To cite this version:}

Katherine Higgie, Andrea Tommasi. Feedbacks between deformation and melt distribution in the crust-mantle transition zone of the Oman ophiolite. Earth and Planetary Science Letters, 2012, 359, pp.61-72. 10.1016/j.epsl.2012.10.003 . hal-00795508

\section{HAL Id: hal-00795508 \\ https://hal.science/hal-00795508}

Submitted on 4 Nov 2021

HAL is a multi-disciplinary open access archive for the deposit and dissemination of scientific research documents, whether they are published or not. The documents may come from teaching and research institutions in France or abroad, or from public or private research centers.
L'archive ouverte pluridisciplinaire HAL, est destinée au dépôt et à la diffusion de documents scientifiques de niveau recherche, publiés ou non, émanant des établissements d'enseignement et de recherche français ou étrangers, des laboratoires publics ou privés. 


\title{
Feedbacks between deformation and melt distribution in the crust-mantle transition zone of the Oman ophiolite
}

\author{
Katherine Higgie*, Andrea Tommasi \\ Geosciences Montpellier, CNRS \& Universite` de Montpellier 2, F-34095 Montpellier Cedex 5, France
}

\begin{abstract}
This study presents microstructural evidence for deformation-controlled melt organization and for changes in olivine deformation associated with the presence of melt in an $80 \mathrm{~m}$ vertical section of the crust-mantle transition zone in the Oman ophiolite. This zone represents an 'end member' case for analyzing feedbacks between deformation and melt distribution in the upper mantle, since it experienced strong shear strains in presence of large melt fractions. It is characterized by a subhorizontal compositional layering at the $\mathrm{mm}$ to meter scale, from weakly impregnated dunites to olivine-rich gabbros, which parallels a pervasive foliation containing a strong stretching lineation. The parallelism between the compositional layering and the foliation, the diffuse limits of the layers, the alignment of elongated plagioclase-rich aggregates devoid of internal deformation structures with the elongation of olivine crystals in the dunitic layers, and the sharp compositional changes across some, but not all layer limits suggest deformation plays an essential role on the development of the layering. The variation on a mm-scale of the olivine crystal preferred orientation (CPO) symmetry as a function of the modal content: from axial-[100] symmetry in layers with $<70 \%$ modal olivine to axial-[010] in more gabbroic levels ( $<40 \%$ olivine), which is repeated over the entire section, implies deformation in presence of variable melt fractions. Axial-[100] olivine CPO in olivine-rich layers is consistent with deformation by dislocation creep under high temperature, low pressure, dry conditions. Axial-[010] olivine CPO patterns imply additional sliding along preferentially wetted (010) grain boundaries, increase in the activity of [001] glide, or transpression localized in the melt-rich layers. Since the change in $\mathrm{CPO}$ symmetry is not accompanied by dispersion, instantaneous melt fractions must have remained $<30-40 \%$ in all layers. The continuous variation in olivine CPO symmetry with decreasing olivine content implies therefore that the former depends on the cumulated strain in presence of melt rather than on the instantaneous melt fraction.
\end{abstract}

\section{Introduction}

Melts play an essential role in the dynamics of extensional plate boundaries. Seismic anisotropy data in the East African rift, for example, implies the presence of aligned melt pockets parallel to the rift trend in the upper mantle (Kendall et al., 2005). Seismic and gravity data consistently imply that up to $5 \%$ volume of melt is present in the uppermost mantle $(4-10 \mathrm{~km})$ beneath the MidAtlantic ridge (Dunn et al., 2005). P-wave tomography models in the East Pacific Rise indicate that melt accumulates both in an upper crustal magma lens and in the topmost mantle, at the crust-mantle transition (Dunn et al., 2000). The above interpretations are supported by petrological studies of both ophiolites (e.g., Boudier et al., 1996) and active ridges (e.g., Drouin et al., 2009). Petrostructural and

\footnotetext{
* Corresponding author.

E-mail address: higgie@gm.univ-montp2.fr (K. Higgie).
}

geochemical studies on peridotite massifs also highlight the role of melt percolation on the compositional evolution and thinning of the subcontinental lithospheric mantle (Le Roux et al., 2007; Soustelle et al., 2009). Small melt fractions, probably organized as to form a layered medium, have been proposed to exist in the lithosphereasthenosphere boundary beneath both continental and oceanic plates on the basis of receiver function data (e.g., Kawakatsu et al., 2009; Rychert et al., 2005).

Melting may have a profound effect on the upper mantle rheology. Deformation experiments show that peridotites strength strongly decreases in presence of melt (e.g., Kohlstedt and Zimmerman, 1996; Scott and Kohlstedt, 2006). Theoretical analyses suggest that a viscosity decrease of one order of magnitude occurs at melt fractions as low as $0.1 \%$ (Rosenberg and Handy, 2005; Takei and Holtzman, 2009). Melt-induced strain weakening in the upper mantle is corroborated by field studies that show spatial changes in melt fraction control strain localization (e.g., Dijkstra et al., 2002; Kaczmarek and Müntener, 2008; Kaczmarek 
and Tommasi, 2011; Kelemen and Dick, 1995; Le Roux et al., 2008; Soustelle et al., 2009).

On the other hand, ductile shearing may enhance permeability favoring melt percolation (Rosenberg and Handy, 2000; Takei, 2005; Tommasi et al., 1994). It may also control the melt distribution. Laboratory experiments showed that shearing leads to melt organization in pockets oriented at low angle to the shear plane at the grain size scale (Kohlstedt and Zimmerman, 1996), and, if length-scales are higher than the compaction length, to segregation, with development of melt-rich and melt-poor bands (Holtzman et al., 2003a, 2003b; Holtzman et al., 2005; Holtzman and Kohlstedt, 2007). Olivine CPO formed in melt-present deformation experiments also differ from those formed under dry conditions; they are weaker and have [100]-axes dispersed in the shear plane, instead of aligned in the shear direction. Melt segregation results in further evolution of the olivine $\mathrm{CPO}$, leading to alignment of [001] parallel to the shear direction.

If active at large scale in the mantle, these feedbacks may have implications for seismic studies, as both the presence of a layered melt-solid structure and variations in the olivine CPO significantly change seismic velocities and anisotropy (e.g., Holtzman and Kendall, 2010; Mainprice, 1997; Tommasi et al., 2006; Vauchez et al., 2000). Deformation-induced melt segregation will also result in a local enhancement of porosity and hence of permeability, allowing for faster melt extraction, and in a highly anisotropic mechanical behavior.

To test for feedbacks between deformations and melt distribution in a natural system, we performed a detailed microstructural study of a section of the crust-mantle (Moho) transition zone
(MTZ) in the Oman ophiolite. This section represents an endmember case for analyzing the deformation of olivine-rich rocks in presence of melt, since it records both high shear strains and melt fluxes (Boudier and Nicolas, 1995).

\section{Geological background}

The Oman-United Arab Emirates ophiolite is the largest and most studied ophiolite in the world. It outcrops over $200 \mathrm{~km}$ in kmsized bodies, displaying the full classic ophiolite sequence (Nicolas et al., 2000). This study concentrates on the mantle-crust transition - the Moho Transition Zone (MTZ, Fig. 1), which locally associates high shear strains and melt fractions as the upwelling mantle is forced away from the ridge axis in a corner flow (Ceuleneer et al., 1988; Jousselin and Mainprice, 1998; Rabinowicz et al., 1987). Its thickness ranges from a few to $>100 \mathrm{~m}$; its upper limit is the base of the continuous layered gabbro section of the lower crust and its base is marked by the transition from dunites to harzburgites (Benn et al., 1988; Boudier and Nicolas, 1995).

The MTZ is formed by interlayered dunites, wehrlites, troctolites, and olivine-rich gabbros, which form lenses, a few $\mathrm{mm}$ to tens of meters thick and several meters to tens of meters long, locally crosscut by wehrlites and by chromite pods (Boudier and Nicolas, 1995). It is interpreted as produced by reactive percolation and accumulation of basaltic melts in the uppermost part of the mantle beneath an active ridge (Boudier and Nicolas, 1995; Korenaga and Kelemen, 1997; Rabinowicz et al., 1987). Field studies show that the MTZ limits and its internal structure (layering, foliation, and

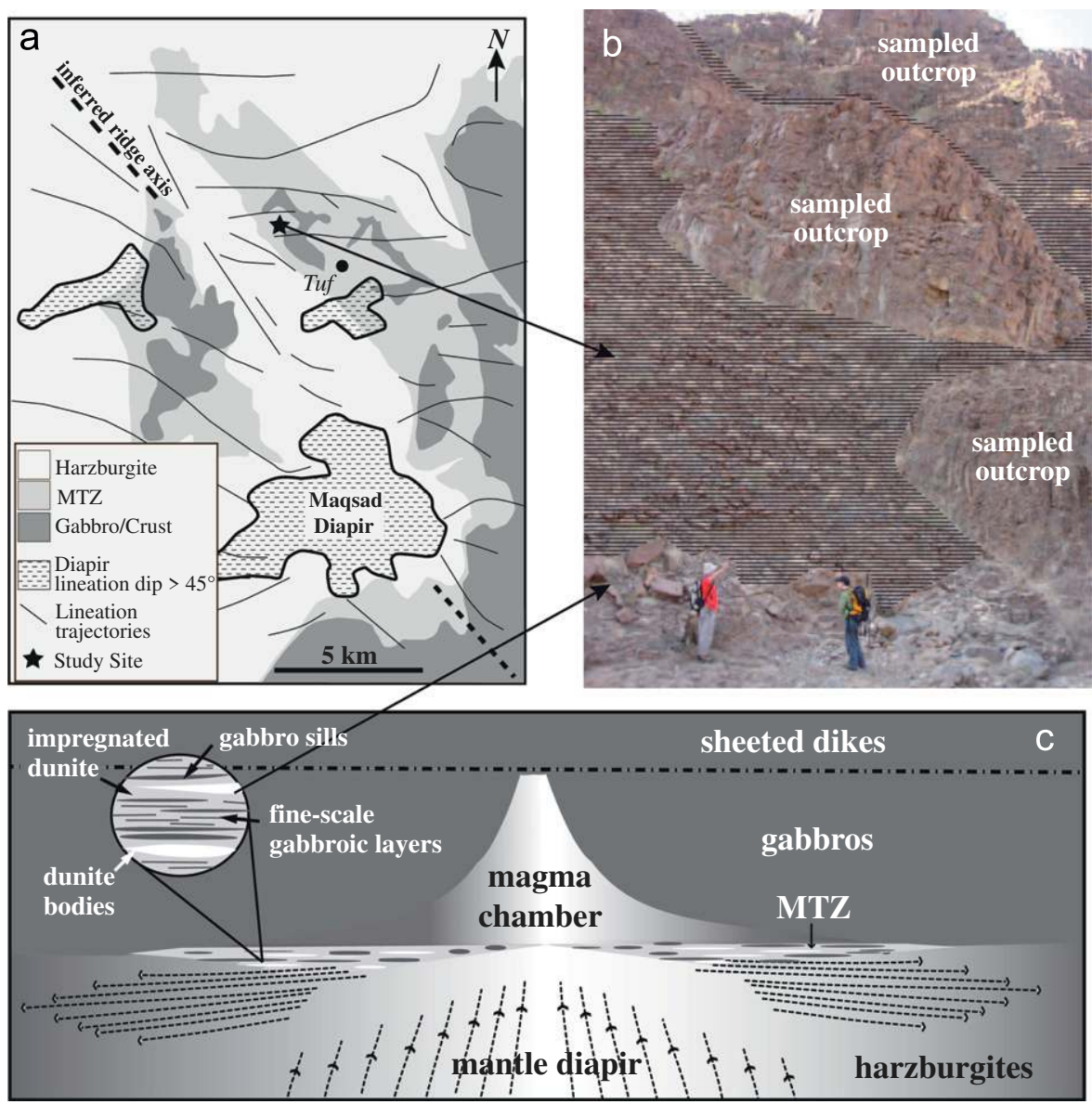

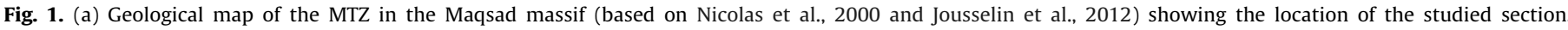

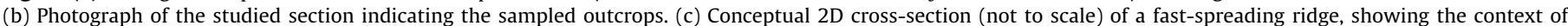
formation of the studied section (F. Boudier, personal communication). 
lineation, when present) are roughly parallel to the regional Moho (Benn et al., 1988; Jousselin et al., 2012). Lineations tend to radiate away from domains with steeply dipping lineations (Fig. 1a), which were proposed to represent mantle diapirs feeding the ridge (Jousselin and Nicolas, 2000). Microstructural studies reveal a range of fabrics and textures, from coarse-grained dunites with strong shape and crystal preferred orientations that record large plastic strains at high-temperature conditions to magmatic textures in gabbroic lenses, as a function of the position relative to the diapirs (Boudier and Nicolas, 1995; Jousselin et al., 2012).

\section{Field observations}

We studied $\mathrm{a} \sim 80 \mathrm{~m}$ thick continuous section of a $\sim 250 \mathrm{~m}$ thick MTZ in the Maqsad massif (Fig. 1b). The studied section is located near Tuf at $\mathrm{N} 23^{\circ} 07^{\prime} 00^{\prime \prime}, \mathrm{E} 57^{\circ} 56^{\prime} 21^{\prime \prime},>5 \mathrm{~km}$ away from the main Maqsad diapir (Fig. 1a). It represents a domain of the MTZ submitted to strong horizontal shearing (Fig. 1c). Harzburgites crop out $\sim 20 \mathrm{~m}$ below the base of the section. The lower crust layered gabbro sequence starts $\sim 150 \mathrm{~m}$ above the top of the section. In between, a few metric to decametric scale gabbroic lenses crop out.

The studied section is characterized by a centimetric to metricscale interlayering of dunites, wehrlites, and olivine-bearing gabbros (Fig. 2a and b). This compositional layering parallels a pervasive subhorizontal foliation (Fig. 2b) containing a lineation trending $\mathrm{N} 110^{\circ} \mathrm{E}$. The foliation is materialized by a sheet-like alteration in the dunitic layers (Fig. 2b) and the lineation by a shape-preferred orientation of plagioclase and clinopyroxene aggregates in the more gabbroic levels (Fig. 2c). The layering is discontinuous; most layers are lens-shaped and cannot be followed laterally for more than a few meters (Fig. 2d). Layer boundaries are generally diffuse (Fig. 2e and f), but asymmetric layers characterized by a sharper upper or lower boundaries as well as continuous changes in modal composition are also observed within the section.

No systematic variations of modal composition, grain size, or layer thickness were observed across the section. 34 oriented samples were collected, sampling as completely the section as possible (Fig. 1b). Some samples contained 2-3 layers with different compositions (Fig. 2e and f). This allowed a detailed study of the compositional and microstructural changes across layer limits. Strong serpentinization of olivine-rich layers resulted in predominance of gabbroic rocks in the sampling, but dunitic and wehrlitic layers are as common as or even more abundant than gabbroic levels in the section.

\section{Modal compositions and microstructures}

The samples were classified into three groups based on their olivine content, which was derived from a joint analysis of EBSD maps and thin-sections. Dunites (sensu lato) are layers containing $>70 \%$ olivine; this group encompasses impregnated dunites
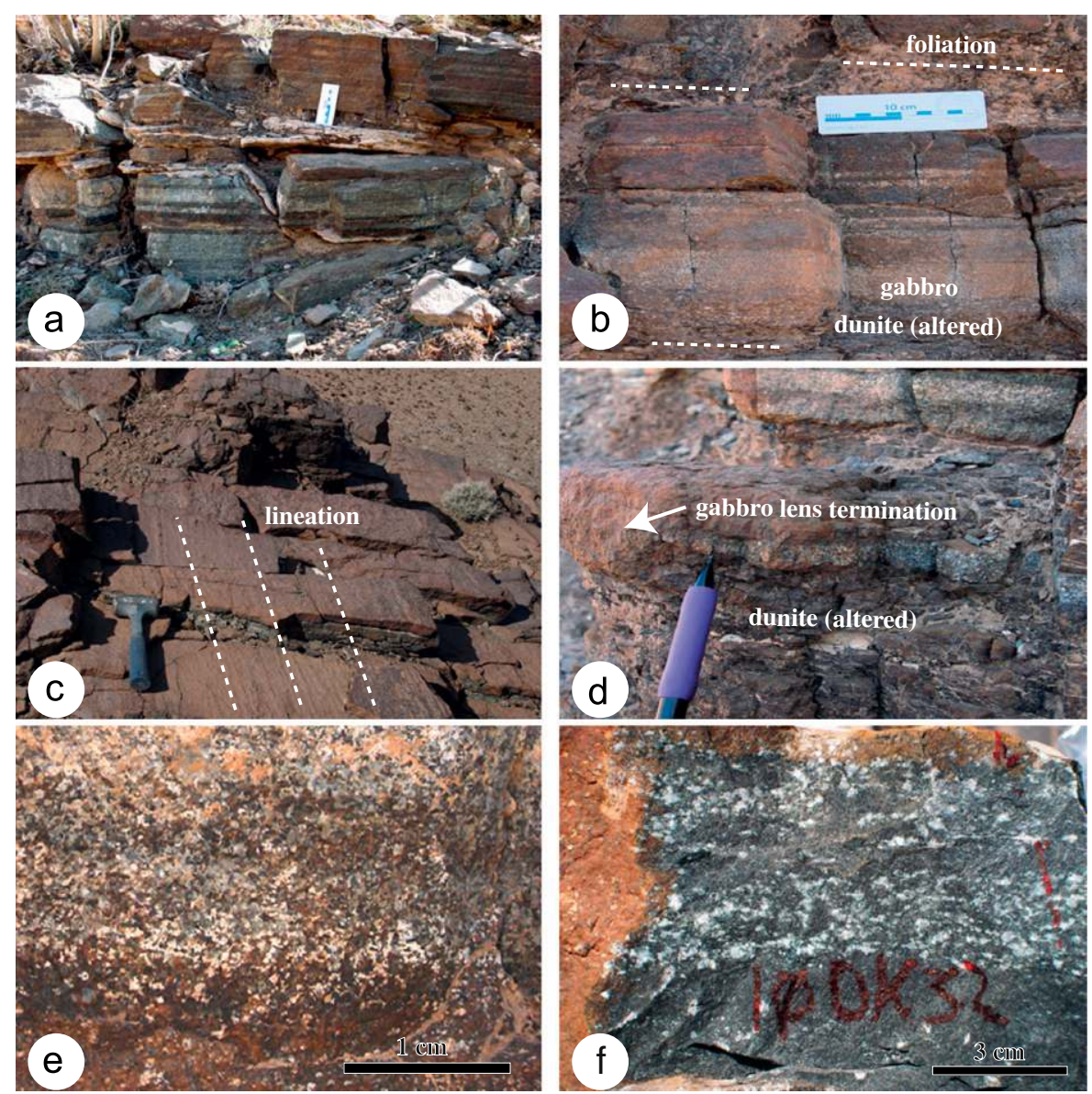

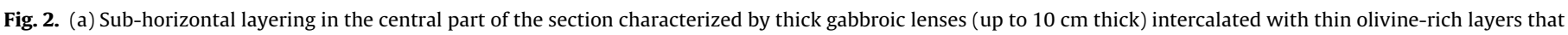

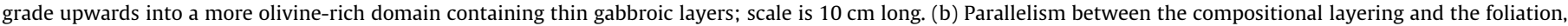

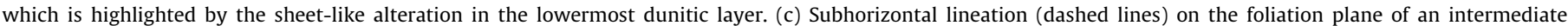

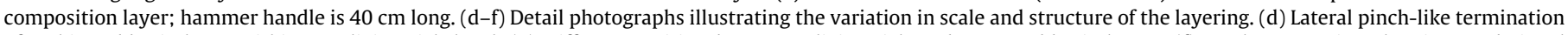

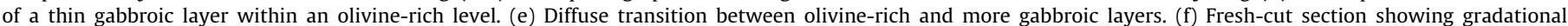
transitions between dunitic and intermediate composition layers; note the preferred orientation of the plagioclase aggregates parallel to the cm-scale layering. 


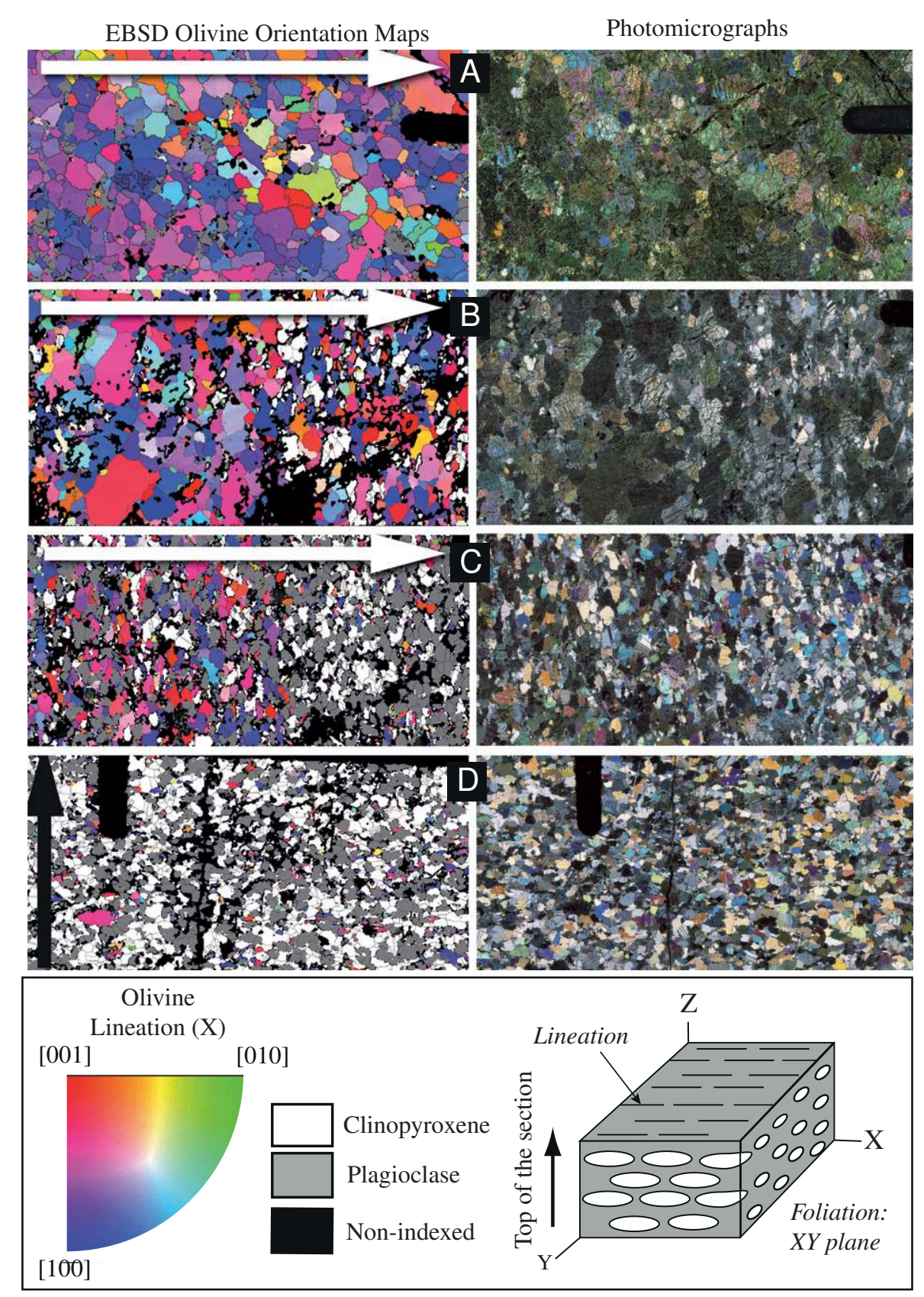

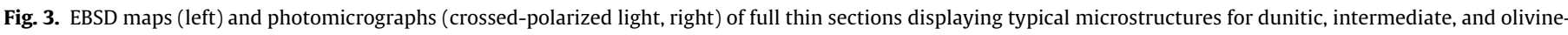

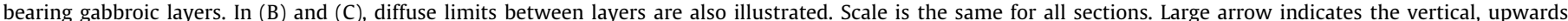

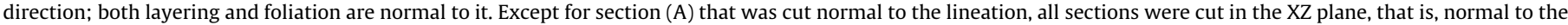

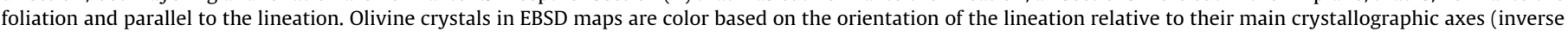

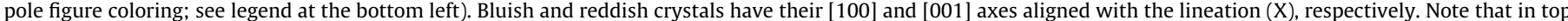

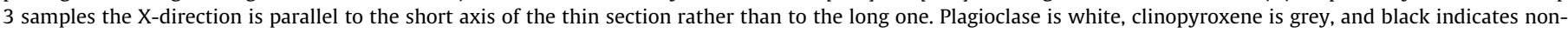

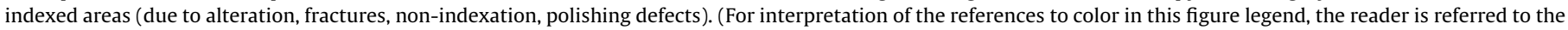
web version of this article.)

ranging from actual dunites ( $>95 \%$ olivine, Fig. 3a) to wehrlites or troctolites. Intermediate composition samples contain between $30 \%$ and $70 \%$ olivine; they are often derived from levels showing continuous compositional variations at the mm-scale (Fig. $3 \mathrm{~b}$ and c). Olivine-gabbros have $<30 \%$ olivine (Fig. $3 \mathrm{~d}$ and upper layer of 3c).

Dunitic layers are coarse-grained and generally strongly serpentinized. All have some clinopyroxene (Fig. 3a) and some also display low degrees of plagioclase impregnation (lower layer of Fig. 3b). Olivine crystals are plurimillimetric. They are usually slightly elongated (aspect ratios may attain 4:1, but are more commonly 2:1), marking the foliation and lineation (Figs. 3b and $4 \mathrm{a}$ ); the elongation is less marked in more wehrlitic samples (Fig. 3a). Most olivine crystals show widely spaced subgrain boundaries normal to the crystal elongation and weak undulose extinction. Grain boundaries are curved, forming festoons (Fig. 4a). $120^{\circ}$ triple junctions are also observed (Fig. 3a). Spinels $(<2 \%)$ are either interstitial or included in olivine. They are small $(<0.1 \mathrm{~mm}$ in diameter), anhedral, and show no preferred orientation. Clinopyroxene and plagioclase are always interstitial; they occur 

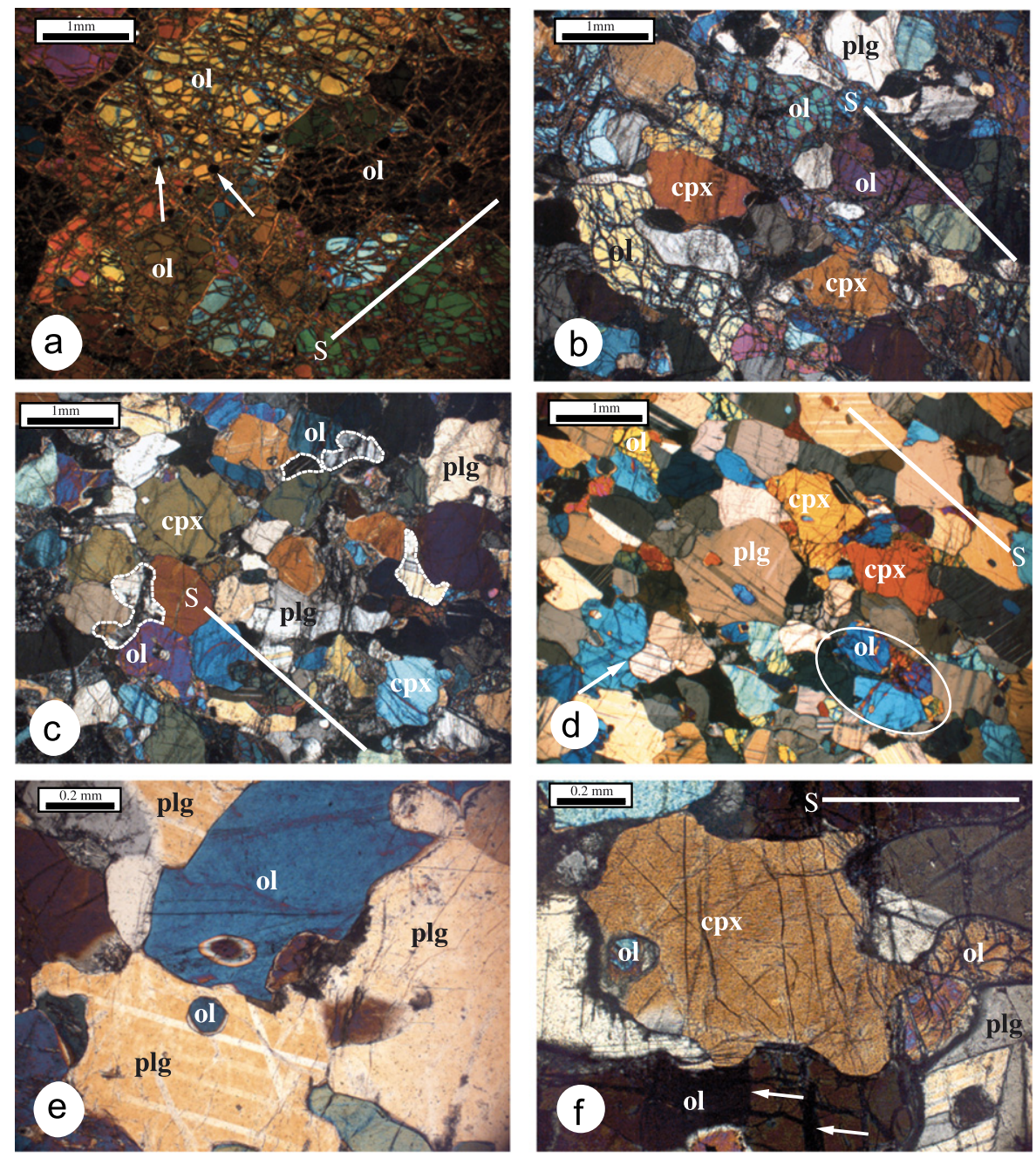

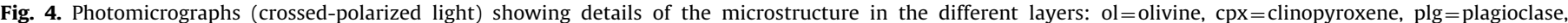

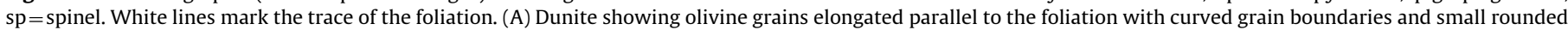

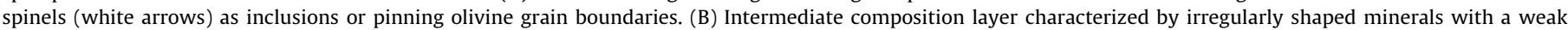

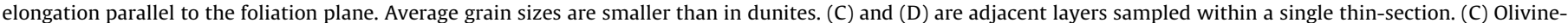

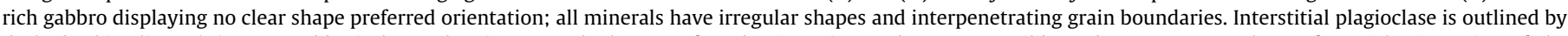

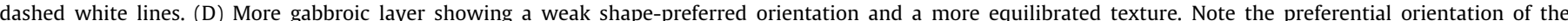

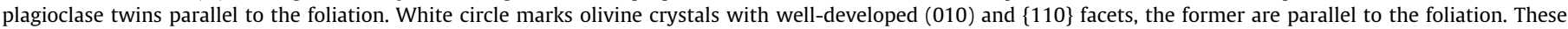

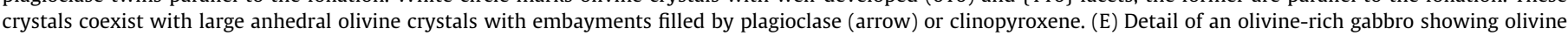

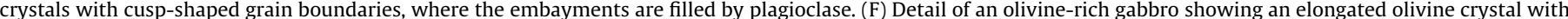

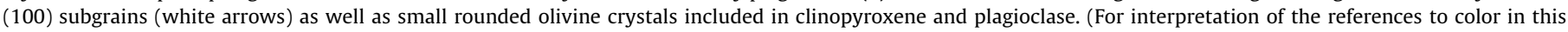
figure legend, the reader is referred to the web version of this article.)

either as oikocrysts enclosing deformed olivine crystals or as anhedral interstitial crystals devoid of intracrystalline deformation features (Fig. 3a).

Intermediate composition samples share microstructural features with both dunites and gabbros (Fig. $4 b$ and c). The average grain size and the elongation of olivine decrease as clinopyroxene and plagioclase become more abundant (Fig. 3b and c). Average grain sizes of all phases are more homogenous than in the dunites. Olivine grains are anhedral, showing cuspshaped boundaries, but still elongated parallel to the foliation (Figs. $3 \mathrm{c}$ and $4 \mathrm{~b}$ ). In some samples, chain-like alignments of olivine crystals mark the foliation. Clinopyroxene and plagioclase are anhedral, usually displaying interstitial shapes that suggest a magmatic origin (Figs. 3b, c and 4b, c). Some samples have, however, a clear planar structure, characterized by a higher fraction of flattened plagioclase crystals with twins subparallel to the foliation and by more elongated olivine crystals (Fig. 3c). Olivine crystals have undulose extinctions and sometimes, subgrains. Although serpentinization hinders the observation of grain boundaries, there is evidence for grain boundary migration as irregular, interpenetrating olivine-olivine contacts (Fig. 4b).

Olivine-gabbros are usually rather homogeneous (Fig. $3 \mathrm{c}$ and d), but may contain 1-2 mm wide anorthositic or dunitic levels that could not be treated separately at the scale of this study. Olivine tends to be smaller ( $\leq 0.8 \mathrm{~mm}$ ) than clinopyroxene and plagioclase $(\leq 1.2 \mathrm{~mm})$. Euhedral crystals with well-developed (010) and $\{110\}$ facets are locally observed (Fig. 4d), but olivine is usually anhedral, displaying cusped grain boundaries (Fig. 4e). It still has a weak shape preferred orientation marking the foliation (Fig. 3d). Subgrains are rarer than in olivine-rich layers, but are observed locally (Fig. 4f). Plagioclase and clinopyroxene have irregular shapes (Fig. 3d) and contain olivine inclusions (Fig. 4e and f). They show a weak shape-preferred orientation (aspect ratios of 1:1.5), marking the foliation and the lineation (Figs. 3d and 4d). Mechanical twins in plagioclase are more common than in olivine-rich layers. They are preferentially 


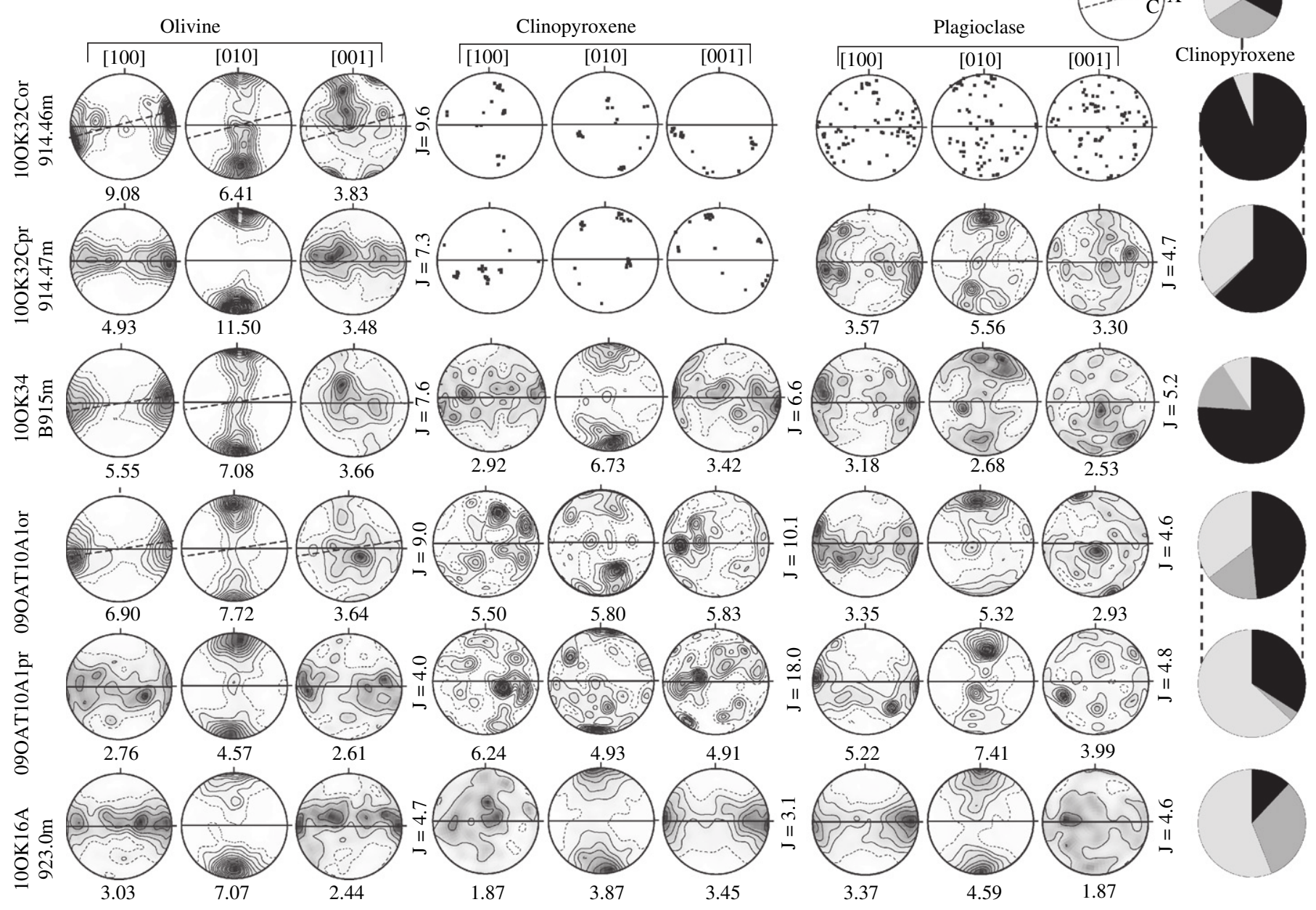

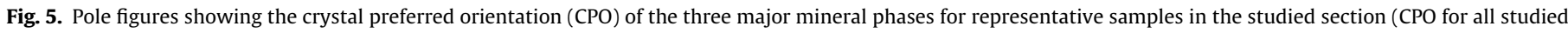

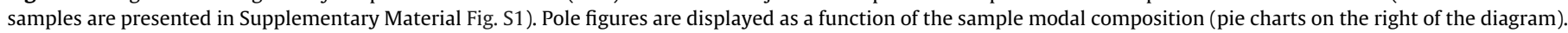

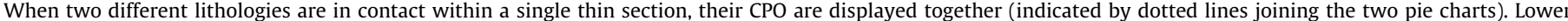

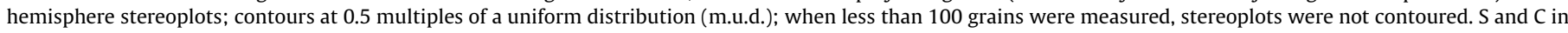

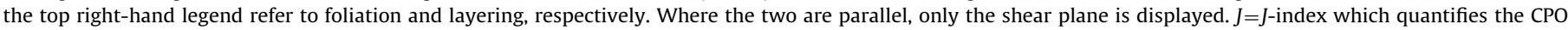
strength, see text and the supplementary methods section for the definition.

aligned in the foliation. These twins are the sole intracrystalline deformation features observable in plagioclase. Clinopyroxene is devoid of intracrystalline deformation features.

\section{Crystal preferred orientations}

Typical crystal preferred orientations (CPO) for olivine, clinopyroxene, and plagioclase in dunites, intermediate composition layers, and olivine gabbros are presented in Fig. 5. Measurement conditions and data treatment, as well as the modal composition and CPO data for all 61 analyzed thin sections as a function of their position in the section are presented as Electronic Supplementary Material (Methods section and Fig. S1).

All samples have a well-developed olivine CPO. Clinopyroxene and plagioclase, where significantly present ( $>5 \%$ ), also show clear CPO although more dispersed than the olivine CPO. Spinel contents in most samples are too low for measurement of a statistically relevant $\mathrm{CPO}$, but samples that have higher contents ( $\leq 80$ grains measured) show a random spinel CPO.

\subsection{Olivine}

In dunites, olivine has an axial-[100] CPO characterized by a strong point concentration of [100] axes subparallel to the lineation and by a girdle distribution of the [010] axis at high angle to it, with a weak maximum subperpendicular to the foliation (Fig. 5). [001] axes are more dispersed than [100] and [010], but form a girdle normal to the lineation with a weak maximum close the foliation plane. A small obliquity between the olivine CPO and the crystals elongation is often observed (Fig. 5). In olivine-bearing gabbros, the olivine [100] axes is more dispersed, forming a girdle in the foliation plane, and the [010] axes tend to concentrate normal to the foliation, resulting in an axial[010] pattern. [001] axes also form a girdle in the foliation plane. Intermediate composition layers have transitional olivine CPO patterns, characterized by a [100] girdle in the foliation plane, but with preservation of a maximum subparallel to the lineation.

Analysis of the orientation distribution of the olivine [100] and [010] axes shows that the transition from axial-[100] to axial[010] olivine CPO patterns happens gradually over a range in olivine modal contents from $70 \%$ to $40 \%$ (Fig. 6). It is, however, very sharp spatially, occurring over a few millimeters following 


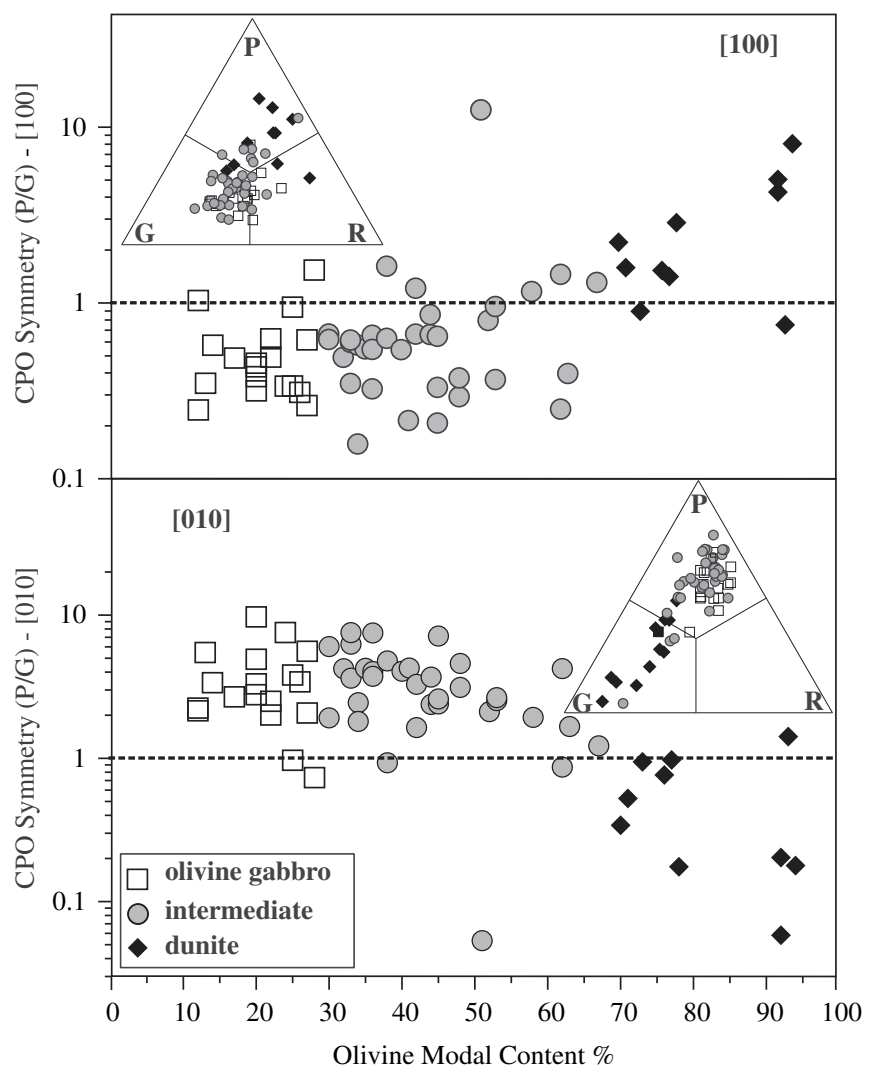

Fig. 6. Variation of symmetry of the olivine $\mathrm{CPO}$, described by the ratio between the Point $(P)$, Girdle $(G)$ components of the distribution of the olivine [100] and [010] axes, function of the olivine modal content. Point (P), Girdle (G) and Random (R) components of the distribution of the olivine [100] and [010] axes are calculated from the eigenvalues $\left(\lambda_{1}, \lambda_{2}, \lambda_{3}\right)$ of the normalized orientation matrix for each crystallographic axis as $P=\lambda_{1}-\lambda_{3}, G=2\left(\lambda_{2}-\lambda_{3}\right)$, and $R=3 \lambda_{3}$ (Vollmer, 1990); they are represented as ternary diagrams (insets).
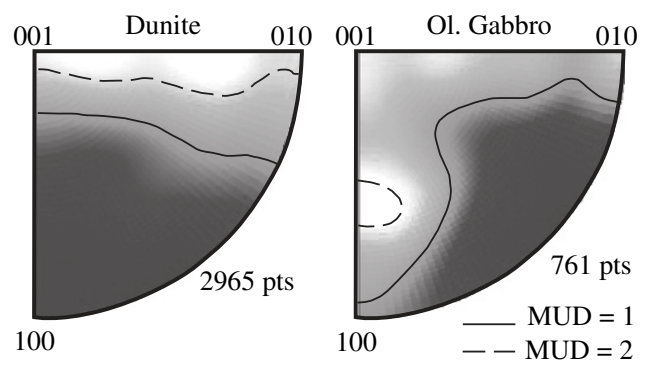

Fig. 7. Inverse pole figures of rotation axes accommodating low-angle misorientations $\left(3-10^{\circ}\right)$ in a dunitic and an olivine-bearing gabbroic layer.

compositional variations in layered samples (e.g., sample $100 K 32 \mathrm{C}$ in Fig. 5). The change in olivine CPO symmetry may be accompanied by a change in rotation axes accommodating low-angle $\left(<10^{\circ}\right)$ misorientations; olivine-rich layers have mainly $\langle 0 \mathrm{VW}\rangle$ rotation axes, whereas olivine-poor layers also show rotations around $\langle\mathrm{UOW}\rangle$ (Fig. 7). There is no correlation between modal composition and the strength of the olivine CPO (Fig. 8a). The $J$-index, which quantifies the CPO strength, ranges between 4 and 12 .

\subsection{Clinopyroxene}

Clinopyroxene has a CPO characterized by a concentration of [001] axes parallel to the lineation and of (010) planes parallel to the foliation (Fig. 5). [100] axes tend to be more dispersed. In

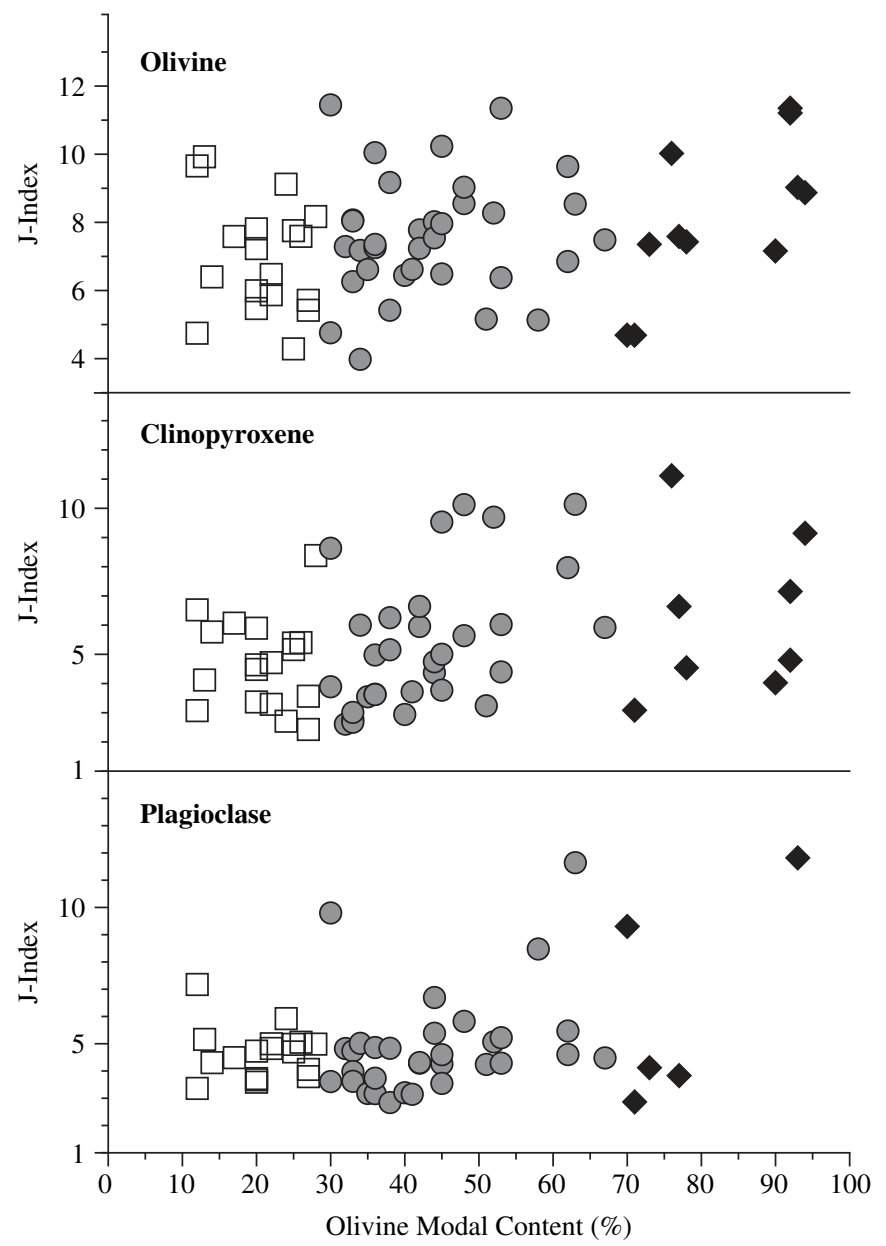

Fig. 8. Strength of the olivine, plagioclase, and clinopyroxene $\mathrm{CPO}$, quantified by the $J$-index, which is the volume-averaged integral of the squared orientation densities (Bunge, 1982). Mantle peridotites usually have olivine $J$-index $\left(J_{\mathrm{Ol}}\right)$ in the range $2-25$, with a peak at $8-10 ; J_{\mathrm{Ol}}>20$ are rare (Ben Ismail and Mainprice, 1998; Tommasi et al., 2000). Symbols as in Fig. 6 (diamonds=dunites, circles $=$ intermediate composition, squares=olivine-gabbros).

layers with $<5 \%$ of clinopyroxene, CPO is almost random. Clinopyroxene $J$-index varies strongly from sample to sample (Fig. 8b). However, data in olivine-rich layers may be biased, because few grains were measured, causing potential $J$-index overestimation. Intermediate and gabbroic layers, which have higher pyroxene contents, show more homogeneous and weaker clinopyroxene CPO.

\subsection{Plagioclase}

In intermediate composition layers and olivine-gabbros, plagioclase has a CPO characterized by a girdle of [100] in the foliation plane with a clear maximum parallel to the lineation and a concentration of [010] normal to the foliation with, in some cases, some dispersion in a plane normal to the lineation (Fig. 5). In layers with $<10 \%$ of plagioclase, plagioclase has an almost random $\mathrm{CPO}$. There is no correlation between the strength of the plagioclase CPO and the modal composition of the layer (Fig. 8c).

\section{Mineral compositions}

Electron microprobe analyses of major and trace element compositions of olivine, clinopyroxene, plagioclase and spinel were carried out on 12 selected thin sections (16 different layers) 

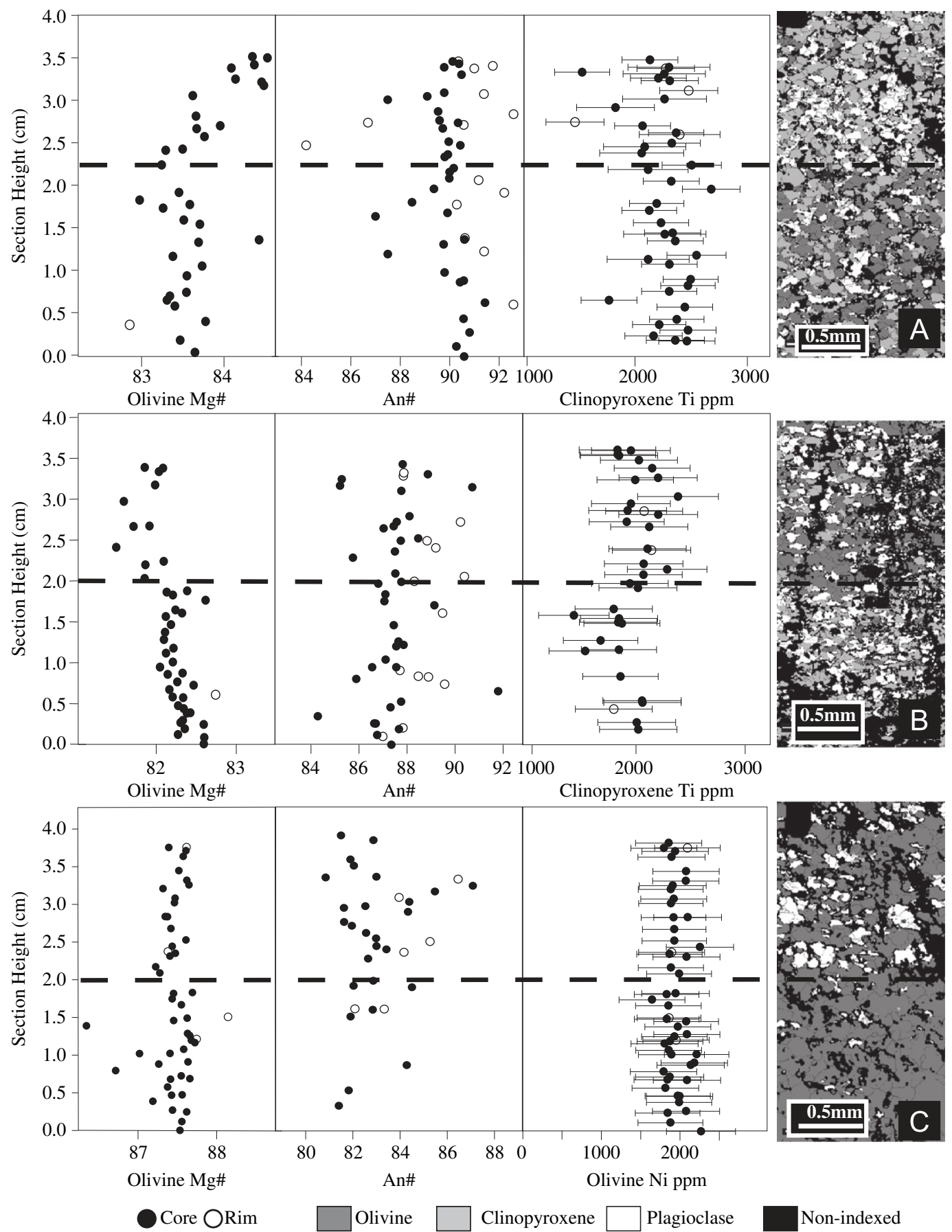

Fig. 9. Variations in mineral compositions across layers limits in three representative thin sections $1 \sigma$ error bars are displayed for trace elements.

representative of the different modal compositions and textures in the section (EPMA acquisition conditions and data are presented as Electronic Supplementary Material - Methods section and Table 1). Mineral compositions are consistent with previous data from the Oman MTZ (Korenaga and Kelemen, 1997). They are as variable within the studied section as the modal composition and mineral fabrics. They also vary strongly at the $\mathrm{cm}$-scale, that is, within a layer or at the layers limits (Fig. 9). Although there are core-rim variations, they tend to be equivalent to the compositional variation among different grains in a layer (Fig. 9). There is no evidence for zoning in plagioclase, an observation confirmed by cathodoluminescence analyses.

Detailed sampling of mineral compositions along transects normal to the layering in three composite samples highlights sharp variations in chemical composition at some layer limits (Fig. 9). It also shows that although there are general trends linking modal and minerals compositions, at the layer scale the trends may change. Gabbroic samples where the layering is marked by variations in the olivine and plagioclase contents are characterized by sharp variations in olivine composition at the layers limits (Fig. 9a and b). Olivine $\mathrm{Mg} \#$ is always low, but it may either increase (from 83.5 to 84.5 , Fig. 9a) or decrease (from 82.2 to 81.8 , Fig. 9b) towards the more plagioclase-rich layer. $\mathrm{Cr}$ content in clinopyroxene also shows weak variations across layer limits (within the measurement error) and opposite behaviors in these two samples. In contrast, the studied transition from a dunitic to an intermediate composition layer (Fig. 9c) is not characterized by changes in olivine $\mathrm{Mg} \#$ or Ni content, but olivine 
composition is more variable in the dunitic layer whereas plagioclase composition is more variable and tend to be more An-rich in the more gabbroic layer.

\section{Discussion}

\subsection{Feedbacks between deformation and melt distribution}

Many processes have been invoked to explain the compositional layering in the MTZ of the Oman ophiolite, ranging from intrusion and fractional crystallization in horizontal fractures associated with a reorientation of the stress field (Ildefonse et al., 1993; Boudier et al., 1996) to melt accumulation during porous flow in a media with variable porosity (Boudier and Nicolas, 1995; Kelemen et al., 1997; Korenaga and Kelemen, 1997; Rabinowicz et al., 1987). Mineral major- and traceelement compositions as well as REE chemistry in the gabbroic lenses favor a compositional layering produced by porous flow in a conductively cooling system, characterized by an interplay between reduction of permeability due to partial crystallization of the melt and continuous melt replenishing (Kelemen et al., 1997; Korenaga and Kelemen, 1997) and reaction with the preexisting harzburgites (Godard et al., 2000).

The present structural observations are consistent with a porous flow origin for the compositional layering, but indicate that the melt distribution in the MTZ is largely controlled by the strong horizontal shearing in the ductile field that characterizes this domain. These observations include: (i) parallelism between the compositional layering and deformation structures (Fig. 2a and $\mathrm{b}$ ), (ii) the preferred orientation of the plagioclase aggregates in the olivine-rich layers (Fig. 2e and f), and (iii) the correlations of the plagioclase and clinopyroxene CPO in the olivine-gabbros and intermediate composition layers with the olivine crystals elongation and CPO in all layers (Fig. 5).

Deformation-controlled melt distribution in a two-phase material submitted to shearing is consistent with experiment data (Holtzman et al., 2003b) and numerical models (Butler, 2009; Katz et al., 2006). It is also corroborated by a recent study by Jousselin et al. (2012), which shows a correlation between macroscopic shapes and fabrics of gabbroic lenses sampled in the Oman MTZ at varying distance from the Maqsad diapir, the fabric strength increasing from isotropic to strongly layered gabbros.

The most striking feature pointing to strong feedbacks between melt distribution and deformation in the studied section is, however, the change in olivine CPO symmetry as a function of modal composition (Figs. 5 and 6). Layers with high olivine contents ( $>70 \%$ ) have axial-[100] patterns, which are typical of mantle rocks deformed in simple shear under high-temperature, moderate pressure conditions (e.g., Tommasi et al., 2000; Zhang and Karato, 1995; Bystricky et al., 2000). In contrast, intermediate composition and gabbroic layers have olivine CPO with axial[010] patterns, similar to those observed in simple shear experiments on olivine-melt aggregates (Zimmerman et al., 1999). This transition in olivine CPO symmetry occurs at the mm-scale (Fig. 5). It cannot therefore be interpreted as due to changes in pressure or temperature (Durham and Goetze, 1977; Mainprice et al., 2005). Water being highly incompatible means deformation of hydrous olivine (Jung and Karato, 2001) is also an unlikely explanation for the axial-[010] CPO in the gabbroic layers. Together, these data point to a change in olivine CPO controlled by the melt content and hence to small-scale variations in the melt content across the section.

Finally, the sharp variations in mineral chemistry characterizing some layer limits point to a component of layer-parallel melt flow (Fig. 9). Numerical models analyzing the effects of buoyancy on shear-induced melt bands (Butler, 2009) show that layer parallel-flow in melt-rich bands is favored by low buoyancy to shear ratios and non-linear rheologies in the solid matrix. These conditions are probably fulfilled in the studied section, which records strong horizontal shearing and has olivine CPO indicative of dislocation creep, implying stress exponents $\sim 3$, as discussed in the next section.

\subsection{Deformation processes: microstructures and crystal preferred orientations}

All major rock-forming minerals show clear CPO that is consistent with the field-measured foliation and lineation (Fig. 5). CPO strength does not depend on the modal composition; only the symmetry of the olivine CPO changes (Fig. 6). An exception is the poikilitic plagioclase and clinopyroxene in impregnated dunites, which random orientation indicates post-kinematic crystallization.

Microstructures in dunites, characterized by elongated olivine crystals with widely-spaced (100) subgrain boundaries and curved grain limits in olivine, are typical of solid-state deformation by dislocation creep at high temperature conditions. Axial[100] olivine CPO patterns in the olivine-rich layers may thus be explained by dislocation creep under high temperature, low pressure, dry conditions (Tommasi et al., 2000). As the plagioclase and clinopyroxene content in the layer increases, olivine grain size decreases. Olivine crystals show cusp-shaped grain boundaries (Fig. 4), suggesting olivine-consuming melt-rock reactions. However, even in gabbroic layers, the largest crystals are still elongated in the foliation and preserve subgrain boundaries (Figs. 3 and 4). In contrast, plagioclase and clinopyroxene in these layers have typical magmatic textures; they lack intracrystalline deformation features, except for a few deformation twins in plagioclase, and often preserve interstitial, interlocking shapes.

The deformation processes active in the melt-rich layers are difficult to unravel due to the very effective textural reequilibration of these samples by grain boundary migration (indicated by the common $120^{\circ}$ triple junctions, Fig. 4) that erased part of the deformation-related features. Grain boundary pinning prevented, however, total re-equilibration of grain shapes. Present grain elongations should therefore be representative of the original ones.

The plagioclase CPO in the gabbroic layers is consistent with the weak shape-preferred orientation of subhedral plagioclase in these lenses. Such fabrics are traditionally interpreted as produced by magmatic flow. They are indeed similar to those developed by magmatic flow in Oman gabbros (Ildefonse et al., 2002) and anorthosites (Morales et al., 2011). If produced by magmatic flow, the alignment of the plagioclase [100] axes with the macroscopic lineation (Fig. 5) would imply that melt flow was essentially layerparallel and normal to the ridge axis. However, magmatic flow is unlikely to produce the clear $\mathrm{CPO}$ of coexisting clinopyroxene (Fig. 5), since the latter, as the latest crystallizing phase, is usually interstitial and displays no shape-preferred orientation (Figs. 3 and 4). Magmatic flow also cannot account for the clear plagioclase and clinopyroxene $\mathrm{CPO}$ in olivine-rich intermediate layers (Fig. 5). The lack of intracrystalline deformation features in both phases also rule out CPO development by solid-state deformation. We propose therefore an alternative explanation whereby the plagioclase and clinopyroxene $\mathrm{CPO}$ result from oriented crystallization in a deforming media (e.g., Fleet, 1983; Kamb, 1959).

Olivine CPO also cannot have a purely magmatic origin. Analysis of products of incomplete melting experiments showed olivine xenocrysts with well developed (010) and $\{110\}$ facets produced by preferential corrosion of olivine along (010) faces and (100) subgrain boundaries plus anisotropic growth (Boudier, 
1991). Euhedral olivine crystals similar to those produced in these experiments are locally observed in gabbroic layers (Fig. 3d). However, most olivine crystals have anhedral shapes with cusped grain boundaries (Fig. 5d), indicating corrosion by the melt and associated crystallization of clinopyroxene and/or plagioclase. This reaction would progressively reduce the aspect ratio of olivine crystals (Fig. 4) and hence, the possibility to form strong magmatic CPO. In addition, although grain interactions in a crystal mush might explain the undulose extinction and subgrains in olivine, the associated strains are too low to produce the strong CPO observed in most layers, independent of their composition.

The continuous change in olivine CPO pattern from axial-[100] to axial-[010] as a function of the olivine content (Fig. 6a and b) is better explained by solid-state deformation accommodated by dislocation creep accompanied by diffusion and limited sliding along melt-wetted grain boundaries (Holtzman et al., 2003a, Takei and Holtzman, 2009). The pre-existing olivine CPO might have resulted in anisotropic melt distribution via preferential corrosion of olivine crystals along (010) planes. Grain boundary sliding along preferentially wetted (010) crystal faces would favor the alignment of these faces in the shear plane and produce rotations around the [010] axis, dispersing both [100] and [001]. Simultaneous activation of [100](010) and [001](010) might also have contributed to the development of the axial-[010] patterns. [001] glide is consistent with [UV0] rotation axes accommodating low-angle misorientations in some gabbroic layers (Fig. 7), but the physical causes favoring the activation of [001] glide in olivine in the presence of melt are still not understood.

A variation in strain regime from simple shear to transpression (Tommasi et al., 1999) may also explain the changes in the olivine CPO. Compaction allowing for extraction of late crystallizing melt fractions may result in transpressive deformation and hence in development of axial-[010] patterns in the melt-rich layers, while melt-poor layers would deform by simple shear, developing axial[100] olivine CPO. Simple shear in the dunitic layers is corroborated by the obliquity between the olivine $\mathrm{CPO}$ and the foliation/lineation (Fig. 5). In the gabbroic layers, CPO and macroscopic fabrics are parallel, which is consistent with a larger component of layer-normal shortening. This model is consistent with the open system behavior inferred from the mineral compositions (Korenaga and Kelemen, 1997 and present data, Fig. 9 and Electronic Supplementary Material). This externally-controlled strain partitioning is, however, different from the one proposed by Holtzman and Kohlstedt (2007), where the dispersion of [100] axes in the shear plane resulted from local out-of-plane stresses due to anisotropic wetting of grain contacts in a system where simple shear is mainly accommodated by melt-assisted grain boundary diffusion creep plus limited sliding along melt-wetted grain boundaries.

Finally, the preservation of a clear olivine CPO in all layers independently of their modal composition (Figs. 5 and 7), implies that the instantaneous melt fraction remained, at all times, below the critical value allowing for loss of cohesion of the solid matrix (20-40\%; e.g., Rosenberg and Handy, 2005). This inference may be reconciled with the observation that many layers contain $>60 \%$ melt-derived phases (plagioclase, clinopyroxene \pm olivine) by considering that both the composition and the CPO evolution are not instantaneous processes, but depend on the melt-rock reactions integrated through time and on the finite strain accumulated in presence of melt, respectively.

\subsection{Comparison with experimental data and models on two-phase systems}

The present observations clearly point to shear-induced melt segregation and to changes in the olivine deformation controlled by the melt distribution in the Oman MTZ. There are, however, significant differences between the present observations in a natural system, the experimental data (Holtzman et al., 2003b; King et al., 2010; Zimmerman et al., 1999), and predictions by numerical models of shear deformation in two-phase aggregates (Butler, 2009; Katz et al., 2006).

Preferentially wetted grain boundaries and melt-rich bands are parallel to the shear plane in nature, rather than inclined at $20^{\circ}$ to it as in experiments and numerical models. In the experiments, melt-rich layers form an anastomosed network that encloses melt-poor lenses, whereas in the Oman MTZ gabbroic and intermediate composition layers form very elongated, but finite lenses (aspect ratios 1:100 or higher, Fig. 2d). Olivine CPO in the Oman MTZ is also much stronger than those formed in simple shear experiments (Holtzman et al., 2003b; King et al., 2010; Zimmerman et al., 1999). Finally, the alignment of [001] parallel to the shear direction observed in experiments with melt segregation also does not exist in our data, where [100] axes, although dispersed in the foliation plane, always present a concentration subparallel to the lineation.

These discrepancies may arise from the lower stresses in the natural system. Boundary conditions also differ; the MTZ is an open system, allowing for melt injection and extraction, whereas both experiments and models consider closed systems. Moreover, anisotropy arising from a preexisting olivine CPO (both models and experiments consider an isotropic starting material) may affect both the deformation (e.g., Tommasi et al., 2009) and the melt distribution.

\subsection{Rheological consequences of shear-induced melt segregation}

At laboratory strain rates, the viscosity of mantle rocks depends exponentially on the melt fraction (Kohlstedt and Zimmerman, 1996; Scott and Kohlstedt, 2006). Theoretical analyses considering the melt distribution anisotropy further predict that melt fractions as low as $0.01 \%$ decrease the shear viscosity by up to an order of magnitude (Takei and Holtzman, 2009). Shear-induced melt segregation producing melt-rich layers parallel to the shear plane should result in an anisotropic viscosity, characterized by a lower resistance for layer-parallel shearing relative to other deformation regimes. Such feedbacks between deformation and melt distribution have been proposed to produce strain localization at the base of the lithosphere as well as lubrication and fast melt extraction paths in extensional plate boundaries (Holtzman and Kendall, 2010).

Clear evidence for strain localization in melt-rich layers is not observed in the studied section. Possible explanations are: (i) the lack of strain markers allowing to quantify the strain distribution between different layers and (ii) the strong textural reequilibration that partially erased the deformation structures. Higher finite strains in the melt-rich layers may, however, be indirectly inferred from the similar intensities of olivine CPO in all layers, if one considers that a large proportion of the deformation in the melt-rich layers has been accommodated by diffusion or sliding along melt-lubricated grain boundaries.

Melt-rich lenses flattened parallel to the foliation or shear plane as those observed in the Oman MTZ will also change the seismic anisotropy response relative to a 'dry' or to an isotropic partially molten medium (Holtzman and Kendall, 2010; Mainprice et al., 1998; Tommasi et al., 2006; Vauchez et al., 2000). P-waves will be faster parallel to the shear plane and slower normal to it. S-waves polarized parallel to the shear plane will be also faster. P-waves propagating and S-waves polarized in the shear plane, as well as S-waves propagating normal to it will, in contrast, show very low anisotropy. 
The present observations show that shear-driven melt segregation occurs in the crust -mantle transition zone beneath an oceanic ridge, which probably contained high instantaneous melt fractions ( $\ll 40 \%$, however). One may question however if this process also occurs at the low instantaneous melt fractions $(<2 \%)$ inferred for a 'normal' upper mantle. Shear-driven melt segregation was observed in experiments with average melt fractions as low as $0.5 \%$ (Holtzman and Kohlstedt, 2007). This process was also proposed to explain the fine-scale pyroxenite layering in the lherzolites from the Lherz massif, which has been interpreted as a fossil lithosphere-asthenosphere boundary (Le Roux et al., 2008). Seismological data also point to shear-induced melt segregation in the asthenosphere and lithospheric mantle. Oriented melt pockets were invoked to explain the high shear wave splitting delay times in the Afar (Kendall et al., 2005; Holtzman and Kendall, 2010). Kawakatsu et al. (2009) further interpreted observed P-S and S-P conversions at the lithosphere-asthenosphere boundary as resulting from a strong velocity reduction for vertically propagating $\mathrm{P}$ - and S- waves due to shear-induced melt segregation at low average melt fractions $(0.25-1.25 \%)$ in the uppermost asthenosphere. Together, these observations suggest that shear-driven melt segregation also occurs under 'normal' asthenospheric conditions.

\section{Conclusion}

This study presents direct microstructural evidence for deformation-controlled melt organization and for changes in olivine deformation in a partially molten natural system. Together, the parallelism between the fine-scale compositional layering and the foliation, the diffuse limits of the different compositional layers, the alignment of elongated plagioclaserich aggregates devoid of internal deformation structures marking a lineation in the intermediate and gabbroic layers subparallel to the elongation of olivine in the dunitic layers, the coherent $\mathrm{CPO}$ of olivine, plagioclase and clinopyroxene in the intermediate and gabbroic layers, and the sharp compositional changes across some, but not all layer limits clearly point to an essential role of the deformation on the development of the layering in the Oman MTZ.

The sharp changes in olivine CPO pattern (at the mm-scale) may only be explained by deformation in presence of variable melt contents. Axial-[100] olivine CPO in olivine-rich layers is consistent with deformation by dislocation creep under high temperature, low pressure, dry conditions. In contrast, axial[010] olivine CPO patterns imply an additional contribution of sliding along preferentially wetted (010) grain boundaries, an increase in the activity of [001] glide, or transpression localized in melt-rich layers. The present observations do not allow discrimination between these processes; they rather suggest concomitant activation of all three processes. Strong olivine CPO characterizes all layers, implying that instantaneous melt fractions always remained below the critical fraction (20-40\%) allowing for the disruption of the solid stress-bearing network. The continuous variation in olivine CPO symmetry over a compositional range (70-40\% modal olivine) indicates therefore that the changes in olivine CPO patterns are controlled by the cumulated strain in the presence of melt rather than on the instantaneous melt fraction.

Analysis of experimental data pointed that deformation-induced melt segregation should induce a strong directional weakening and seismic anisotropy in the upper mantle (Holtzman and Kendall, 2010; Holtzman et al., 2005). The present observations show that this process also occurs in nature, but that melt-rich layers form parallel to the shear plane rather than at an angle to it. They also show that deformation in presence of melt tends to disperse the olivine [100] and [001] axes in the shear plane, producing axial[010] patterns, but does not result in dominant concentration of [001] along the shear direction. The present observations concern, however, an environment submitted to high shear strains in presence of large melt fractions; caution should be used when extrapolating these conclusions to the upper mantle, where instantaneous melt fractions are significantly lower.

\section{Acknowledgments}

We thank A. Vauchez, F. Boudier, and A. Nicolas for help in the field and frequent discussions. Exchanges with M. Godard, B. Ildefonse, and D. Mainprice also contributed to the present work. We thank $O$. Müntener and an anonymous reviewer for constructive comments. D. Mainprice provided software for analyzing/ plotting CPO data. C. Nevado and D. Delmas supplied high quality polished thin sections for EBSD measurements. L. Morales helped with EBSD data acquisition and treatment. Electron microprobe analyses were carried out with the help of C. Merlet at the Service Microsonde Sud, Universite Montpellier 2. The research leading to these results has received funding from the Initial Training Network (ITN) Crystal2Plate, an FP7-funded Marie Curie Action under Grant Agreement no. PITN-GA-2008-215353. The EBSDSEM national facility in Montpellier is supported by the Institut National de Sciences de l'Univers (INSU) du Centre National de la Recherche Scientifique (CNRS), France and by the Conseil Régional Languedoc-Roussillon, France.

\section{Appendix A. Supporting information}

Supplementary data associated with this article can be found in the online version at http://dx.doi.org/10.1016/j.epsl.2012.10.003.

\section{References}

Ben Ismail, W. Mainprice, D. 1998. An olivine fabric database: an overview of upper mantle fabrics and seismic anisotropy. Tectonophysics 296, 145-157.

Benn, K., Nicolas, A., Reuber, I., 1988. Mantle-crust transition zone and origin of wehrlitic magmas: evidence from the Oman ophiolite. Tectonophysics 151, 75-85.

Boudier, F., 1991. Olivine xenocrysts in picritic magmas - an experimental and microstructural study. Contrib. Mineral. Petrol. 109, 114-123.

Boudier, F., Nicolas, A., 1995. Nature of the moho transition zone in the Oman ophiolite. J. Petrol. 36, 777-796.

Boudier, F., Nicolas, A., Ildefonse, B., 1996. Magma chambers in the Oman ophiolite: fed from the top and the bottom. Earth Planet. Sci. Lett. 144, 239-250.

Bunge, H.J., 1982. Texture Analysis in Materials Sciences. Buttleworth, London.

Butler, S.L., 2009. The effects of buoyancy on shear-induced melt bands in a compacting porous medium. Phys. Earth Planet. Inter. 173, 51-59.

Bystricky, M., Kunze, K., Burlini, L., Burg, J.-P., 2000. High shear strain of olivine aggregates: rheological and seismic consequences. Science 290, 1564-1567.

Ceuleneer, G., Nicolas, A., Boudier, F., 1988. Mantle flow patterns at an oceanic spreading center: the Oman peridotites record. Tectonophysics 151, 1-26.

Dijkstra, A.H., Drury, M.R., Frijhoff, R.M., 2002. Microstructures and lattice fabrics in the Hilti mantle section (Oman ophiolite): evidence for shear localization and melt weakening in the crust-mantle transition zone? J. Geophys. Res. 107

Drouin, M., Godard, M., Ildefonse, B., Bruguier, O., Garrido, C.J., 2009. Geochemical and petrographic evidence for magmatic impregnation in the oceanic lithosphere at Atlantis Massif, Mid-Atlantic Ridge (IODP Hole U1309D, 30 $\mathrm{N}$ ). Chem. Geol. 264, 71-88.

Dunn, R.A., Lekic, V., Detrick, R.S., Toomey, D.R., 2005. Three-dimensional seismic structure of the Mid-Atlantic Ridge (35N): evidence for focused melt supply and lower crustal dike injection. J. Geophys. Res. 110, B09101, http://dx.doi.or $\mathrm{g} / 10.1029 / 2004 \mathrm{JB} 003473$.

Dunn, R.A., Toomey, D.R., Solomon, S.C., 2000. Three-dimensional seismic structure and physical properties of the crust and shallow mantle beneath the East Pacific Rise at 9'30'N. J. Geophys. Res. 105, 23537-23555.

Durham, W.B., Goetze, C., 1977. Plastic flow of orientated single crystals of olivine 1; Mechanical data. J. Geophys. Res. 82, 5737-5753.

Fleet, M.E., 1983. Preferred crystallographic orientation for crystallisation under nonhydrostatic stress. Phys. Status Solidi (a) 76, 151-156. 
Godard, M., Jousselin, D., Bodinier, J.-L., 2000. Relationships between geochemistry and structure beneath a palaeo-spreading center: a study of the mantle section in the Oman ophiolite. Earth Planet. Sci. Lett. 180, 133-148.

Holtzman, B.K., Groebner, N.J., Zimmerman, M.E., Ginsberg, S.B., Kohlstedt, D.L., 2003a. Stress-driven melt segregation in partially molten rocks. Geochem. Geophys. Geosyst. 4, 8607, http://dx.doi.org/10.1029/2001GC000258.

Holtzman, B.K., Kendall, J.M., 2010. Organized melt, seismic anisotropy, and plate boundary lubrication. Geochem. Geophys. Geosyst. 11, Q0AB06, http://dx.doi.o rg/10.1029/2010GC003296.

Holtzman, B.K., Kohlstedt, D.L., 2007. Stress-driven melt segregation and strain partitioning in partially molten rocks: effects of stress and strain. J. Petrol. 48, 2379-2406.

Holtzman, B.K., Kohlstedt, D.L., Morgan, J.P., 2005. Viscous energy dissipation and strain partitioning in partially molten rocks. J. Petrol. 46, 2569-2592.

Holtzman, B.K., Kohlstedt, D.L., Zimmerman, M.E., Heidelbach, F., Hiraga, T., Hustoft, J., 2003b. Melt segregation and strain partitioning: implications for seismic anisotropy and mantle flow. Science 301, 1227-1230.

Ildefonse, B., Mainprice, D., de Burgos, C.M.G., 2002. Crystallographic preferred orientations and seismic properties of gabbroic rocks. AGU meeting, San Francisco.

Ildefonse, B., Nicolas, A., Boudier, F., 1993. Evidence from the Oman ophiolite for active mantle upwelling beneath a fast-spreading ridge. Nature 370, 51-53.

Jousselin, D., Morales, L.F.G., Nicolle, M., Stephant, A., 2012. Gabbro layering induced by simple shear in the Oman ophiolite moho transition zone. Earth Planet. Sci. Lett. 331-332, 55-66.

Jousselin, D., Nicolas, A., 2000. The Moho transition zone in the Oman ophioliterelation with wehrlites in the crust and dunites in the mantle. Mar. Geophys. Res. 21, 229-241.

Jousselin, D., Mainprice, D., 1998. Melt topology and seismic anisotropy in mantle peridotites of the Oman ophiolite. Earth Planet. Sci. Lett. 164, 553-568.

Jung, H., Karato, S.-i., 2001. Water-induced fabric transitions in olivine. Science 293, 1460-1463.

Kaczmarek, M.-A., Tommasi, A., 2011. Anatomy of an extensional shear zone in the mantle, Lanzo massif, Italy. Geochem. Geophys. Geosyst. 12, Q0AG06, http://dx.doi.org/10.1029/2011GC003627.

Kaczmarek, M.-A., Müntener, O., 2008. Juxtaposition of melt impregnation and high temperature shear zone in the upper mantle: field and petrological constraints from the Lanzo peridotite (NItaly). J. Petrol. 49, 2187-2220.

Kamb, W.B., 1959. Theory of preferred crystal orientation developed by crystallization under stress. J. Geol. 67, 153-170.

Katz, R.F., Spiegelman, M., Holtzman, B., 2006. The dynamics of melt and shear localization in partially molten aggregates. Nature 442, 676-679.

Kawakatsu, H., Kumar, P., Takei, Y., Shinohara, M., Kanazawa, T., Araki, E., Suyehiro, K., 2009. Seismic evidence for sharp lithosphere-asthenosphere boundaries of oceanic plates. Science 324, 499-502.

Kelemen, P.B., Dick, H.J.B., 1995. Focused melt flow and localized deformation in the upper mantle: juxtaposition of replacive dunite and ductile shear zones in the Josephine peridotite, SW Oregon. J. Geophys. Res. 100, 423-438.

Kelemen, P.B., Koga, K., Shimizu, N., 1997. Geochemistry of gabbro sills in the crust-mantle transition zone of the Oman ophiolite: implications for the origin of the oceanic lower crust. Earth Planet. Sci. Lett. 146, 475-488.

Kendall, J.M., Stuart, G., Ebinger, C., Bastow, I., Keir, D., 2005. Magma-assisted rifting in Ethiopia. Nature 433, 146-148.

King, D.S.H., Zimmerman, M.E., Kohlstedt, D.L., 2010. Stress-driven melt segregation in partially molten olivine-rich rocks deformed in torsion. J. Petrol. 51, $21-42$.

Kohlstedt, D.L., Zimmerman, M.E., 1996. Rheology of partially molten mantle rocks. Ann. Rev. Earth Planet. Sci. 24, 41-62.

Korenaga, J., Kelemen, P.B., 1997. Origin of gabbro sills in the Moho transition zone of the Oman ophiolite: implications for magma transport in the oceanic lower crust. J. Geophys. Res. 102, 27729-27749.

Le Roux, V., Bodinier, J.L., Tommasi, A., Alard, O., Dautria, J.M., Vauchez, A., Riches, A.J.V., 2007. The Lherz spinel lherzolite: refertilized rather than pristine mantle. Earth Planet. Sci. Lett. 259, 599-612.
Le Roux, V., Tommasi, A., Vauchez, A., 2008. Feedback between melt percolation and deformation in an exhumed lithosphere-asthenosphere boundary. Earth Planet. Sci. Lett. 274, 401-413.

Mainprice, D., 1997. Modelling the anisotropic seismic properties of partially molten rocks found at mid-ocean ridges. Tectonophysics 279, 161-179.

Mainprice, D., Ismail, W.B., Wagner, F., 1998. The relationship between olivine textures and seismic anisotropy in a database of upper mantle rocks. in: Schwarzer, R.A. (Ed.), Texture and Anisotropy of Polycrystals, pp. 681-686.

Mainprice, D., Tommasi, A., Couvy, H., Cordier, P., Frost, D.J., 2005. Pressure sensitivity of olivine slip systems and seismic anisotropy of Earth's upper mantle. Nature 433, 731-733.

Morales, L.F.G., Boudier, F., Nicolas, A., 2011. Microstructures and crystallographic preferred orientation of anorthosites from Oman ophiolite and the dynamics of melt lenses. Tectonics 30, TC2011, http://dx.doi.org/10.1029/2010TC002697.

Nicolas, A., Boudier, F., Ildefonse, B., Ball, E., 2000. Accretion of Oman and United Arab Emirates ophiolite - discussion of a new structural map. Mar. Geophys. Res. 21, 147-180.

Rabinowicz, M., Ceulener, G., Nicolas, A., 1987. Melt segregation and flow in mantle diapirs below spreading centers: evidence from the Oman ophiolite. J. Geophys. Res. 92, 3475-3486.

Rosenberg, C.L., Handy, M.R., 2000. Syntectonic melt pathways during simple shearing of a partially molten rock analogue (Norcamphor-Benzamide) J. Geophys. Res. 105, 3135-3149.

Rosenberg, C.L., Handy, M.R., 2005. Experimental deformation of partially melted granite revisited: implications for the continental crust. J. Metam. Geol. 23, $19-28$.

Rychert, C.A., Fischer, K.M., Rondenay, S., 2005. A sharp lithosphere-asthenosphere boundary imaged beneath eastern North America. Nature 436, 542-545.

Scott, T., Kohlstedt, D.L., 2006. The effect of large melt fraction on the deformation behavior of peridotite. Earth Planet. Sci. Lett. 246, 177-187.

Soustelle, V., Tommasi, A., Bodinier, J.L., Garrido, C.J., Vauchez, A., 2009. Deformation and reactive melt transport in the mantle lithosphere above a large-scale partial melting domain: the Ronda Peridotite Massif, Southern Spain. J. Petrol. 50, 1235-1266.

Takei, Y., 2005. Deformation-induced grain boundary wetting and its effects on the acoustic and rheological properties of partially molten rock analogue. J. Geophys. Res. 110, B12203, http://dx.doi.org/10.1029/2005JB003801.

Takei, Y., Holtzman, B.K., 2009. Viscous constitutive relations of solid-liquid composites in terms of grain boundary contiguity: 3 . Causes and consequences of viscous anisotropy. J. Geophys. Res. 114, B06207, http://dx.doi.org/10.1029/ 2008JB005852.

Tommasi, A., Vauchez, A., Fernandes, L.A.D., Porcher, C.C., 1994. Orogen-paralle strike-slip faulting and synkinematic magmatism in the Dom Feliciano Belt Southern Brazil. Tectonics 13, 421-437.

Tommasi, A., Tikoff, B., Vauchez, A., 1999. Upper mantle tectonics: three-dimensional deformation, olivine crystallographic fabrics and seismic properties. Earth Planet. Sci. Lett. 168, 173-186.

Tommasi, A., Knoll, M., Vauchez, A., Signorelli, J., Thoraval, C., Logé, R., 2009. Structural reactivation in plate tectonics controlled by olivine crystal anisotropy. Nat. Geosci. 2, 423-427.

Tommasi, A., Mainprice, D., Canova, G., Chastel, Y., 2000. Viscoplastic selfconsistent and equilibrium-based modeling of olivine lattice preferred orientations: implications for the upper mantle seismic anisotropy. J. Geophys. Res. 105, 7893-7908.

Tommasi, A., Vauchez, A., Godard, M., Belley, F., 2006. Deformation and melt transport in a highly depleted peridotite massif from the Canadian Cordillera: implications to seismic anisotropy above subduction zones. Earth Planet. Sci. Lett. 252, 245-259.

Vauchez, A., Tommasi, A., Barruol, G., Maumus, J., 2000. Upper mantle deformation and seismic anisotropy in continental rifts. Phys. Chem. Earth Pt. A 25, 111-117.

Vollmer, F.W., 1990. An application of eigenvalue methods to structural domain analysis. Geol. Soc. Am. Bull. 102, 786-791.

Zimmerman, M.E., Zhang, S., Kohlstedt, D.L., Karato, S., 1999. Melt distribution in mantle rocks deformed in shear. Geophys. Res. Lett. 26, 1505-1508.

Zhang, S., Karato, S., 1995. Lattice preferred orientation of olivine deformed in simple shear. Nature $375,774-777$. 